\title{
KANT, ROUSSEAU E AS BASES ESTÉTICAS DO PENSAMENTO
}

KANT, ROUSSEAU AND THE AESTHETIC BASIS OF THOUGHT

KANT, ROUSSEAU Y LAS BASES ESTÉTICAS DE PENSAMIENTO

\author{
Pedro Paulo da Costa Corôa \\ Professor Doutor da Universidade Federal do Pará (UFPA) \\ pcoroa@ufpa.br
}

RESUMO: O nosso objetivo é mostrar como a questão relativa ao gosto pode ser encontrada, enquanto forma particular de juízo, na obra de Rousseau, em especial, no Emílio. Em decorrência disso, tudo o que nós aprendemos sobre a gênese moderna do chamado juízo de reflexão estético, identificado à Crítica do juízo, de Kant, se não exige uma correção, obriga-nos, pelo menos, a reconhecer, antes do esforço crítico, o surpreendente e certeiro tratamento do tema por parte de Rousseau.

PALAVRAS-CHAVE: Rousseau. Kant. Gosto. Juízo. Reflexão.

ABSTRACT: The aim of this study was to examine the issue regarding esthetic taste as being a form of judgment, in particular in Rousseau's work Emile. As a result most of what we know concerning the modern origin of judged of esthetic reflection, as defined in Kant's Critique of judgment, although not requiring a revision, at least obliges us to recognize the critical, surprising, and discerning treatment of the topic by Rousseau.

KEYWORDS: Rousseau. Kant. Esthetic taste. Judgment. Reflection.

RESUMEN: Nuestro objetivo es demostrar cómo la cuestión del gusto se puede encontrar, cómo una forma particular de juicio, en la obra de Rousseau, en particular, el Emilio. Cómo resultado, todo lo que hemos aprendido sobre la génesis moderna del juicio estético, identificado a la Crítica del Juicio, si no requiere una corrección nos obliga a reconocer el increíble tratamiento del tema por Rousseau, antes del esfuerzo crítico.

PALABRAS CLAVE: Rousseau. Kant. Gusto. Juicio. Reflexión. 


\section{KANT, ROUSSEAU E AS BASES ESTÉTICAS | Pedro Paulo da Costa Corôa}

Como o faz Ernst Cassirer, em O problema Jean-Jacques Rousseau, a primeira coisa que nos vêm ao pensamento, quando tentamos encontrar um vínculo entre o citoyen de Genève e Kant, é a frase em que o alemão chama o suíço de "Newton do mundo moral". Em Kant und Rousseau, baseado no testemunho de Herder sobre as aulas de Kant na década de sessenta, Cassirer afirma, com razão, que mesmo uma obra como $A$ nova Heloisa possuía, na ótica kantiana, um conteúdo essencialmente moral:

\footnotetext{
[...] seguramente (sicherlich) Kant leu A nova Heloisa de modo distinto de como o fizeram a maioria de seus contemporâneos e daqueles que a leram depois. O centro de gravidade desta obra não estava, para ele, na romântica história de amor do começo e, sim, na segunda parte moral que a encerra. Ele não via esta última [moral] como um mero acréscimo externo com o qual Rousseau teria desfigurado sua obra, desmantelando seu efeito artístico. Era incapaz de ver em $A$ nova Heloisa um simples romance sentimental (keinen bloss sentimentalen Roman) e uma glorificação da paixão. (CASSIRER, 1991, p. 16).
}

Certo da "profunda influência que Rousseau exerceu sobre Kant", Cassirer conclui que "Kant acreditava dever a Rousseau não apenas certas opiniões doutrinais e, sim, um giro decisivo em sua trajetória intelectual, ao indicar-lhe um caminho que então não haveria de abandonar" (CASSIRER, 1991, p. 3).

O caminho aqui indicado, obviamente, é o da filosofia moral. Contudo, o que nos propomos fazer agora é outro tipo de aproximação entre esse dois dos mais importantes pensadores modernos. Nosso propósito é mostrar o lado "esteta" de Rousseau, de modo a sugerir o quanto a sua concepção de gosto de que fala em $A$ nova Heloisa se coaduna com a análise por ele feita das formas mais elementares de pensar - e de linguagem, diga-se - de que é capaz o homem, o que podemos comprovar pelo Livro IV do Emílio e no póstumo Ensaio sobre a origem das línguas. Cremos poder mostrar, inclusive por razões de ordem sistemática e de coerência conceitual, como a afirmação de Kant que "o juízo de gosto é estético" pode ser reconhecida nos elementos com que lida Rousseau, em suas obras comentadas em Königsberg, ainda na fase pré-crítica do filósofo alemão.

De modo algum pretendemos com isso que Kant seja considerado um "discípulo" de Rousseau, afinal cada um deles é mestre de si mesmo. O que queremos dizer é que ambos estavam em uma tal sintonia intelectual que era inevitável conduzirem suas reflexões para bases comuns. A tese que nos orienta é que Rousseau, precocemente, e Kant, em plena maturidade, deram-se conta de que o pensamento original e livre é aquele que mais próximo está de sua "naturalidade" e que, portanto, toda forma disciplinada de pensar, ou de julgar, como a científica - e, até mesmo, a moral -, tem sob si a sustentá-la um estado de consciência, ou como diz Kant no § 9 da Analítica do Belo, "uma suscetibilidade do estado-da-mente na representação dada", que só podemos nomear com uma palavra: sentimento (Gefühl). Só ele pode, ursprünglich, ser reconhecido como princípio, ainda que indeterminado, de tudo que pensamos determinadamente - seja pelo Entendimento (Verstand), seja pela Razão (Vernunft).

Esses dois filósofos, que em plena Aufklärung ousaram relativizar a antes garantida soberania da ciência, alteraram a nossa crença na hierarquia tradicional dos saberes constitutivos da filosofia, ao redimensionarem o peso aí atribuído às bases sensíveis dos nossos juízos. Quer as pessoas estejam conscientes disso, quer não, estamos particularmente convictos de que é o resultado da análise desses dois pensadores extraordinários o que explica a possibilidade histórica tanto da poética reflexiva de Hölderlin - valorizada por Heidegger no período final de sua vida acadêmica -, quanto do Romantismo e até o viés antidoutrinal buscado pela filosofia contemporânea. E essa busca, em todos, conduziu a filosofia para a investigação estética e artística. 


\section{KANT, ROUSSEAU E AS BASES ESTÉTICAS | Pedro Paulo da Costa Corôa}

É para tratar das possibilidades de transformação da e na Filosofia - em uma época em que isso, simplesmente, deveria parecer a coisa mais inesperada - por meio de dois pensadores absolutamente surpreendentes, que resolvemos fazer algumas considerações sobre a importância que tem, na modernidade, a fundamentação estética do pensamento. E para dar mais ênfase a esse poder de surpreender, atrevemo-nos a tratar disso onde, aparentemente, o conceito de reflexão estética jamais teria sido investigado: no pensamento de Rousseau. O apoio sistemático à exposição por nós apresentada, por sua vez, não poderia ser outro que o kantiano, imediatamente reconhecido como fonte do Romantismo alemão e, com isso, de toda uma série de modificações que afetam, até hoje, a nossa maneira de perceber a atividade filosófica.

Quando observamos a forma como evoluiu a história da filosofia, a primeira constatação que fazemos é que o desenvolvimento de quase todos os sistemas tradicionais segue uma trajetória que vai da crítica às formas sensíveis de cognição e ajuizamento ao estabelecimento de critérios cada vez mais abstratos que nos garantam um uso rigoroso e disciplinado do pensamento. A ideia fixa de que a Filosofia deveria, algum dia, tornar-se uma ciência strictu sensu, uma epistéme, dominou praticamente todos os projetos a ela voltados, de Platão até o final século XVIII, pelo menos. Nós aprendemos - e aceitamos sem vacilar - que o programa crítico estabelecido por Kant foi o que promoveu uma mudança radical nesse quadro, revolucionando, como ele mesmo gostava de dizer, o modo tradicional de pensar e entender a natureza particular da filosofia. E um ponto fundamental - posto que coordenador - na estratégia revolucionária kantiana é a valorização da Sensibilidade, com a precisa determinação de seu caráter autônomo - ainda que interligado - no conjunto das faculdades humanas.

Esse maior apreço pelos sentidos - excluído, por certo, na razão prática - tem, em Kant, dois registros bem distintos: um na Crítica da razão pura, de 1781, e outro na Crítica do Juízo - ou da Faculdade de julgar -, de 1790. No primeiro caso, tratava-se, apenas, de mostrar a independência funcional dos sentidos como fontes de representações, ou seja, de intuições. O que Kant tem em mente na Estética Transcendental é um tipo especial de nexo entre a forma geral dessas representações sensíveis e àquelas originadas, também exclusivamente, no Entendimento, definido como uma faculdade que tem por finalidade estabelecer as regras que tornam nossos pensamentos, ou, se quisermos, nossos juízos, potencialmente, objetivos. De acordo com a tese central da Primeira crítica, essa potencialidade só se atualiza, ou seja, se efetiva, em cooperação com a Sensibilidade. Há, portanto, entre Sensibilidade e Entendimento mútua dependência, ao mesmo tempo em que, como nos reafirma o § 22 dos Prolegômenos, "compete aos sentidos intuir [anzuschauen]; ao entendimento, pensar [zu denken]". (KANT, 2006: Prol, AA 04: 304).

No jogo entre essas duas faculdades, na medida em que a questão principal é o que outorga ao nosso pensamento objetividade científica, a Sensibilidade não passa, nesse caso, de uma fonte - particular, sem dúvida - de representações cuja destinação é o mero preenchimento material da forma vazia dos conceitos do Entendimento. É o poder desfrutado pelo Entendimento de reunir, segundo suas próprias leis, a diversidade dispersa de fenômenos de modo a torná-los inteligíveis que lhe dá a condição privilegiada de faculdade superior, o que mantém a Sensibilidade, ainda, como o lado inferior na estrutura das nossas faculdades. Apesar da importância concedida por Kant aos sentidos no processo cognitivo, eles ainda aparecem como ancilla do Entendimento.

De todo modo, é importante nunca esquecer que a Crítica da razão pura é só a primeira das obras que compõem o projeto kantiano em seu todo, e não há erro mais grave e limitador para a nossa compreensão do pensamento de Kant do que condensá-lo em uma única obra, confundindo, 


\section{KANT, ROUSSEAU E AS BASES ESTÉTICAS | Pedro Paulo da Costa Corôa}

assim, a filosofia critica com uma epistemologia. A verdade é que só com a Crítica do Juízo a revolução no modo de pensar proposta por Kant atinge toda sua magnitude, de modo que é a própria imagem da filosofia - seu conceito - que passa a se desenhar de uma forma inteiramente nova e, até mesmo, invertida, ganhando, graças a uma alteração na relação de dependência entre Entendimento e Sensibilidade, seu sentido completo, isto é, sistemático. Na Terceira crítica, a independência funcional dos sentidos, que nos homens, pelo menos, sempre cobra um vínculo qualquer com o pensamento - ou nossa faculdade de julgar -, exibe, para que se dê esse elo indispensável, todo o seu diferencial e originalidade. Afinal, agora, ao invés de nos fornecer múltiplos casos para um princípio unitário e regulador sediado no Entendimento e previamente dado por ele - o que exige o predomínio do conceito -, é a Sensibilidade que passa a fornecer a base de apoio para pensamentos cada vez mais múltiplos e variados, uma vez que livremente concebidos fora da Gesetzgebung que compõe o acordo lógico-transcendental.

A estabilidade para as funções do juízo, que antes era buscada na universalidade abstrata de conceitos concebidos quase que hermeticamente no interior das estruturas lógicas do Entendimento - com o risco constante de hipóstases -, passa a ser encontrada na singularidade indiscutível do que é apreendido pelos sentidos, na medida em que dessa apreensão possa resultar em nós um sentimento [Gefüh/], por meio de cuja representação extraímos uma espécie particular de ideia, posto que tem a ver não com coisas e sim com o nosso próprio estado de ânimo. Com isso, a Crítica do Juízo, literalmente, vira a filosofia - e com ela, a própria Metafísica e sua história - de cabeça para baixo, como que restabelecendo à Sabedoria (Sophia), como a chama Aristóteles, as mesmas condições que tinha na Grécia pré-platônica, ou seja, na Hélade plasmada culturalmente pelos poetas.

No Livro A de sua Metafísica, Aristóteles, a quem muitos reconhecem como o autor da primeira história filosófica da filosofia, surpreende-nos em nossa própria percepção viciada da tradição, ao borrar - para, depois, quase "corrigir" - as fronteiras que supostamente separam o pensamento rigoroso - filosófico - do pensamento mítico, dominado pela força da imaginação (phantasía) em lugar das regras da razão. Como, aliás, já o fizera Platão, são inúmeras as passagens, no primeiro livro, em que Aristóteles intercala referências estritamente filosóficas e poéticas, no afã de nos fazer reconhecer, por meio delas, em seus predecessores, o interesse e uma espécie de impulso natural do pensamento para certos princípios e certas causas (ARISTÓTELES, 2002, A 1, 982a).

E o que dá à pequena história do pensamento narrada pelo estagirita um caráter intrinsecamente filosófico é a substituição da preocupação cronológica pela sistemática, fazendo de sua teoria das quatro causas o elo vinculante entre todos os pensadores citados. É assim que Aristóteles, para nossa surpresa, incorpora a poesia e os poetas à tradição filosófica a que ele mesmo dá continuidade, fato que vem a se repetir a partir de meados do século XVIII, graças, por certo, à Theoretische Ästhetik de Baumgarten, mas sob a influência ainda mais direta e efetiva da Crítica do Juízo e do idealismo, como nos atestam as obras dos primeiros românticos alemães. O certo é que "o fim da metafísica", como ciência, para o qual a Terceira crítica é a contraprova mais radical que a Dialética Transcendental o tinha sido, parece nos pôr frente a um horizonte que anula a distância que nos separa de Aristóteles. Kant, ao fazer com que o sentimento e a subjetividade, preponderantes nas questões de estética e filosofia da arte, ocupem o espaço antes dominado pelo poder essencialmente restritivo da objetividade do sujeito transcendental, como que inverte a ordem histórica e "evolutiva" da filosofia, tornando quase indistintas as figuras do philósophos e do philómythos, ou seja, do poeta - poietés (ARISTÓTELES, 2002, A 2, 982 b 15-20).

No $\S 47$ da Terceira crítica, Kant vai buscar justamente em Homero a prova da "superioridade" liberdade - do pensamento poético (estético), relativamente a capacidade lógico-transcendental do Entendimento, cuja estrutura nos oferece a base canônica para a ciência de Newton. Escreve Kant: 


\title{
KANT, ROUSSEAU E AS BASES ESTÉTICAS | Pedro Paulo da Costa Corôa
}

\begin{abstract}
[...] tudo aquilo que Newton expôs em sua obra imortal sobre os princípios da filosofia natural, por mais poderosa cabeça que seja requerida para inventar tais princípios, pode-se perfeitamente aprender; mas não se pode aprender a fazer poemas com espírito [geistreich dichten lernen], por mais exaustivas que sejam todas as prescrições da arte poética e por mais excelentes que sejam seus modelos. A causa disso é que, todos os passos que Newton teve de dar, desde os primeiros elementos da geometria até suas grandes e profundas descobertas, ele poderia tornar inteiramente claros, não somente a si mesmo, mas a todos os outros, e demonstrá-los determinadamente para seus sucessores; nenhum Homero, porém, ou Wieland, pode indicar como suas ideias, ricas em fantasia e, no entanto, ao mesmo tempo, repletas de pensamento, surgem e se reúnem em suas cabeças, isto porque ele mesmo não o sabe e, portanto, também não pode ensinar a nenhum outro. (KANT, 2006: KU, AA 05: 308-309)
\end{abstract}

Como se vê, na última crítica, é Homero - principal referência na paidéia grega -, e não Newton, como era de se crer, que aparece como o grande símbolo do gênio criativo e livre da humanidade. Ao fazer isso, a Crítica do Juízo subverte, em seu valor e importância, toda a hierarquia de domínios que se manteve hegemônica - apesar de sua crise infindável - desde o começo da Filosofia. No fundo, Kant torna-se, na passagem de uma crítica a outra, cada vez mais consciente de que quanto mais objetivo é o pensamento, ou seja, quanto maior o rigor que ele nos impõe, mais limitados estamos em nossa capacidade de julgar e, com ela, em nossa imaginação - que está na base de todas as operações do espírito, como reconhece, antes dele, Rousseau (ROUSSEAU, 1971, p. 56) e, depois dele, Fichte. Essa base fornecida por nossa facultas imaginandi, chamada por Baudelaire de "a rainha das faculdades" - La reine des facultes (BAUDELAIRE, 1980, p. 750) -, é indissociável da liberdade, ou melhor, da heautonomia, gozada pela Urteilskraft. A Terceira crítica, tomada nessa perspectiva, parece querer confirmar, com Aristóteles - mas também com Platão no Protágoras (316 d) - que o filósofo é o herdeiro intelectual natural do poeta, o que faz do impulso metafísico originário de toda nossa cultura uma manifestação de ordem estética, antes de assumir uma forma lógica abstrata, consciente e deliberada.

Portanto, é a amplitude do chamado "juízo estético" - ou de gosto -, tema central na Crítica do Juízo e indissociável em nossas representações sensíveis, que melhor define a natureza do pensamento - quando o consideramos em sua plena liberdade. Nesse registro, o pensar nunca é, como na ciência, a obrigação do conhecer. Por isso, a heautonomia do Juízo é a afirmação de sua liberdade originária, o que fica evidente se representada frente às restrições legais - lógicas - do Entendimento e da Razão. O juízo de gosto é, na verdade, um pensamento ainda "selvagem", daí seu caráter casual (contingente) e regulativamente inefetivo, quase regellos, como, aliás, costuma-se definir a Einbildungskraft.

A faculdade humana de sentir prazer e desprazer que se ordena finalística e, ao mesmo tempo, livremente, no Juízo, é um modo de pensamento que serve de subsolo para uma subjetividade judicativa que só os constrangimentos produzidos pela experiência histórica da humanidade forçaram a emergir, de modo a nos levar a forjar regras abstratas e "aéreas" para a autodeterminação do nosso pensamento com vistas a uma concordância meramente externa (objetiva) que, antes, na tranquilidade da vida em isolamento, não nos eram de modo algum necessárias. Não por acaso, a evolução histórica da humanidade é, no Ensaio sobre a origem das línguas, de Rousseau, concomitante à evolução da lógica e da gramática. É para podermos viver juntos que a nossa Urteilskraft, inicialmente orientada apenas sensível e subjetivamente, passa a considerar seus conteúdos na perspectiva do Fürwahrhalten, só então ela vai à busca de uma unidade comum de representações a que chamamos objetividade, mas à custa de, de certo modo, estreitar (condicionar) nosso pensamento. 


\title{
KANT, ROUSSEAU E AS BASES ESTÉTICAS | Pedro Paulo da Costa Corôa
}

Quando pensamos no contexto do qual extraímos o conceito moderno de gosto, o reconhecemos facilmente nessa trajetória evolutiva, interna ao sistema kantiano. Sua concepção decorre de uma verdadeira arqueologia transcendental que vai da Primeira à Terceira crítica, e que nos mostra quão recente, especializada e condicionada é a forma de pensar que chamamos científica. O projeto crítico - da análise da razão científica ao juízo estético - representa um recuo cada vez mais profundo às formas originais do nosso pensamento, até expô-lo em sua freie Gesetzmässigkeit.

Mas o que é mesmo que Kant chama de juízo de gosto ou estético? Na Primeira introdução à Crítica do Juízo, opondo-o ao juízo lógico-científico, Kant diz que:

\begin{abstract}
Um juízo estético, em universal, pode [...] ser explicado como aquele juízo cujo predicado jamais pode ser conhecimento (conceito de um objeto) - embora possa conter as condições subjetivas para um conhecimento em geral. Em um tal juízo o fundamento de determinação é a sensação. Mas há somente uma única assim chamada sensação que jamais pode tornar-se conceito de um objeto, e esta é o sentimento de prazer ou desprazer. Esta [sensação] é meramente subjetiva, enquanto toda demais sensação pode ser usada para conhecimento. (KANT, 2006: EEKU, AA 20: 224).
\end{abstract}

ou seja, pode sujeitar-se à unidade objetiva de um conceito.

Como se deixa evidenciar pelo simples mapeamento das obras críticas de Kant, a importância do sentimento e, com ele, a "descoberta" de uma função "lata" para o pensamento, é o resultado de um longo processo analítico. Isso garante, em termos sistemáticos, o rigor e a necessidade de fixar as raízes do nosso poder de julgar em uma função que o distinga de qualquer outra faculdade para que ele, o juízo - pensamento -, seja por si mesmo possível. Por isso ele é um modo de pensar que embora nos seja comum (sensus communis), não o é no sentido de tornar o que pensamos uma representação comum, ou seja, um conceito. Ele tem que ser anterior à fixação de qualquer conceito, uma vez que é graças a ele que o "comparar e manter juntas dadas representações, seja com outras, seja com sua faculdade de conhecimento" torna um conceito possível (KANT, 2006: EEKU, AA 20: 211).

A facultas dijudicandi, portanto, é, por excelência, o poder produtivo do nosso pensamento. Ela é da ordem do nous poietikós, que, como nos diz Aristóteles no seu Peri psychês (De anima), para ser compreendido, exige uma analogia com a natureza, afinal, "na natureza como um todo, distingue-se inicialmente algo que serve de matéria a cada gênero (e isso é o que é em potência todos os seres do gênero), e em seguida uma outra coisa que é a causa e o agente porque ela os produz todos [os gêneros], situação que tem como exemplo a arte relativamente à matéria por ela modificada" (ARISTÓTELES, 1995, 430 a 10). É a mesma analogia utilizada por Kant, ao falar "Da técnica do Juízo como fundamento da técnica da natureza" (KANT, 2006: EEKU, AA 20: 219).

O Juízo, afirma Kant, procede "artisticamente" quando põe objetos dados sob conceitos, ou seja, quando busca para eles referências de unidades que lhes deem uma forma (eidos) genérica. Só que ele o faz "segundo o princípio universal, mas ao mesmo tempo indeterminado, de uma ordem final da natureza em um sistema, como que em favor de nosso Juízo", quer dizer, apenas subjetivamente. Portanto, a base da reflexão (Überlegen) do nosso Juízo, na medida em que não possui, ainda, um conceito que lhe sirva de regra e o determine - como são os casos de Entendimento e Razão -, essa base, dizíamos, só pode estar no sentimento do nosso estado interno no ato do próprio refletir. Aqui o sentimento aparece como redobro da necessidade subjetiva do Juízo e o julgar é tanto mais heautônomo quanto mais se afirma como permanência nessa subjetividade. É assim que, para a Urteilskraft pelo menos, tudo começa. 
III

Tudo o que parece ter custado tanto esforço a Kant, exigindo dele três obras monumentais para a correta composição do conceito de Filosofia, tudo isso, dizíamos, podemos encontrar quase que de pronto em Rousseau. Enquanto Kant finaliza sua reflexão com a valorização dos sentidos e a determinação, no juízo de gosto, da superioridade do sentimento sobre o conceito, em Rousseau esse sempre foi o ponto de partida. Nas palavras de Cassirer, "ele tomou consciência da força do sentimento demasiado cedo e com demasiada profundidade para que pudesse se entregar a ele sem resistências" (CASSIRER, 2007, p. 115). Sua desconfiança, quanto ao caráter limitador da ciência e suas consequências para a cultura humana, vem exposta desde o Discurso sobre as ciências e as artes. Infelizmente, foi justamente o Primeiro discurso que cristalizou os preconceitos com os quais suas obras são, até hoje, interpretadas. A ideia de que seus pensamentos são paradoxais, que não há unidade entre suas obras e que suas reflexões são apenas opiniões idiossincráticas indiferentes a qualquer avaliação objetiva, quase condena a um juízo gratuito a admiração que Kant admite ter pelo filósofo suíço. Talvez tenha feito pouco eco a advertência de Kant de que é preciso persistir na leitura de suas obras de modo a separar nelas a beleza do discurso (efeito estético) e suas cadeias de razões (KANT, 2006: AA 22: 30).

Cassirer adverte que não se fará justiça a Rousseau vendo-se nele apenas

o propagador de um novo evangelho do 'sentimento' que fazia frente à cultura do entendimento do século XVIII. Pois, neste sentido vago, 'sentimento' será uma mera palavra de ordem, insuficiente para designar a autêntica originalidade da problemática filosófica de Rousseau. Esta problemática não surge porque ele se abandone sem mais a essa nova força que o impulsiona e anima, e sim porque se interroga sobre seu fundamento e sua legitimidade. $E$ essa legitimidade não é assumida por Rousseau sem restrições. (CASSIRER, 2007, p. 114-115).

É menosprezar a inteligência de Rousseau imaginar que o assentar toda a série de seus pensamentos no sentimento é fruto de uma atitude instintiva e irrefletida. Seguindo a leitura de Cassirer a respeito da inserção da obra de Rousseau na cultura do século XVIII, diríamos que é por conta de uma espécie o conservadorismo intelectual da época que sua obra foi tão atacada, posto que filosoficamente desqualificada. Ele introduz uma profunda desconfiança entre os crentes no poder transformador da razão científica.

Com Rousseau desloca-se o centro intelectual da época, nega-se tudo o que dava a ela estabilidade e segurança interior. Ele não modificou seus resultados, mas atacou suas raízes intelectuais. Por isso, a resistência contra ele foi historicamente necessária e legitima: onde Rousseau julgava ver uma "conspiração" tramada contra ele, havia na verdade uma reação cuja origem e justificação se encontrava no mais íntimo instinto de autoconservação intelectual da época. (CASSIRER, 2007, p. 114).

Mesmo depois da Terceira crítica, tratar filosoficamente o sentimento era um problema, como atesta uma carta de Schiller, em fevereiro de 1793, ao príncipe Christian Von Augustenburg:

Poucos são aqueles nos quais o termo sentimento da beleza não é sufocado pela abstração, e menos ainda os que estimam o esforço de filosofar sobre suas sensações. Tenho que esquecer inteiramente que sou ajuizado por tais homens, e posso desenvolver minhas ideias e sentimentos apenas para espíritos livres e serenos que se encontram acima do pó das escolas e guardam em si as centelhas da pura nobreza humana. (SCHILLER, 2009, p. 61). 


\section{KANT, ROUSSEAU E AS BASES ESTÉTICAS | Pedro Paulo da Costa Corôa}

É em vista dessa dificuldade, natural à mentalidade do período, que Cassirer se vê levado a afirmar que Rousseau "inaugura uma nova época na história do pensamento europeu. A partir daí, está aberto o caminho para a época da sensibilidade (Empfindsamkeit), para o 'Sturm und Drang' e para o Romantismo alemão e francês" (CASSIRER, 2007, p. 110). Mas isso só pode se mostrar filosoficamente consistente, se formos além da retórica "anticientífica" do Primeiro discurso. Para isso, a fonte principal é, sem dúvida, o Emílio. No Livro IV, Rousseau expõe uma verdadeira teoria da gênese da reflexão e do juízo, como a levada a efeito por Kant na última crítica. Partindo da dificuldade em encontrar um acordo entre os vários sistemas que ambicionam explicar o mundo em toda sua complexidade, Rousseau pergunta:

\footnotetext{
Mas quem sou eu? Que direito tenho de julgar as coisas? E o que determina meus juízos? Se eles são arrastados, forçados pelas impressões que recebo, canso-me em vão com essas pesquisas, elas não se realizarão, ou se realizarão por si mesmas sem que eu me intrometa para dirigi-las. Devo, pois, voltar o olhar primeiro para mim, a fim de conhecer o instrumento de que me quero servir e saber até que ponto posso confiar em seu uso. (ROUSSEAU, 1971, p. 188).
}

Rousseau constata que a primeira ideia que fazemos de nós mesmos, ou seja, da fonte dirigente e determinante de todo juízo possível, que é o "eu", essa "ideia", é um sentimento! Divergindo da orientação lógica suposta pelo cogito cartesiano por considerá-la uma perspectiva tardia, Rousseau sentencia: "Existo e tenho sentidos pelos quais sou afetado. Eis a primeira verdade que me atinge e com a qual sou forçado a concordar". Então, pergunta: "Terei um sentimento próprio de minha existência, ou só a sinto por minhas sensações?" (ROUSSEAU, 1971, p. 188). É clara a diferença aqui feita entre sensação e sentimento. É porque "minhas sensações passam-se em mim", que "me fazem sentir minha existência". Como diz Rousseau, mesmo que os objetos que distingo de mim mesmo - do eu - "não passem de ideias, continua sendo verdade que essas ideias não sou eu".

Mas que tipo de relação pode haver entre mim e minhas ideias, além, é claro, das ideias entre si? Afinal, pela "sensação, os objetos oferecem-se a mim separados, isolados, tais como existem na natureza". Ou seja: na sensação, cada objeto é exclusivo. Rousseau quer saber então porque e como "coloco-os uns sobre os outros para julgar sua diferença ou semelhança e geralmente todas as suas relações"? (ROUSSEAU, 1971, p. 188). Nos termos do De anima, de Aristóteles, a questão é saber o que torna os dados singulares da natureza suscetíveis de reunirem-se em um gênero de seres, quer dizer, representados na unidade do conceito. Afinal, "Perceber é sentir", mas, "comparar é julgar; julgar e sentir não são a mesma coisa" (ROUSSEAU, 1971, p. 188). Julgar é, para usar a linguagem da lógica, transpor o singular em particular, tirá-lo do isolamento para integrá-lo, pelo pensamento, em um todo, ou torná-lo parte de um todo - da universalidade do conceito, ou do gênero, como diz Aristóteles. Ora, isso é, segundo Kant, a vocação natural da Urteilskraft, o que a instaura, permitindo, aos poucos, que representemos em um "sistema empírico" - antes da vigência do "sistema lógico" do Entendimento - "a diversidade e heterogeneidade das leis empíricas” (KANT, 2006: EEKU, AA 20: 209).

Para Rousseau, a chave que nos permite passar da esfera do sentimento à esfera do juízo, "a faculdade distintiva do ser ativo ou inteligente é o poder de dar sentido à palavra é" (ROUSSEAU, 1971, p. 188). Esse poder, diz ele, é a "força para dobrar [os objetos] um sobre o outro", sem o que a alma fica passiva diante dos objetos, "nunca os comparará, não os julgará" (ROUSSEAU, 1971, p. 188). Essa ação instauradora do juízo - forma de tudo o que "é" genericamente, segundo Rousseau - não é o reflektieren, que Kant define, vimos, como o "comparar (zu vergleichen) e manter juntas (zusammen zu halten) dadas representações (gegebene Vorstellunges)", cujo resul- 


\section{KANT, ROUSSEAU E AS BASES ESTÉTICAS | Pedro Paulo da Costa Corôa}

tado é o conceito? E, arremata Rousseau: "Que se dê este ou aquele nome a essa força do meu espírito que aproxima e compara minhas sensações, que seja chamada atenção, meditação, reflexão, ou como se quiser, sempre será verdade que ela está em mim e não nas coisas, que sou eu que a produzo, embora só a produza por ocasião da impressão que fazem sobre mim os objetos" (ROUSSEAU, 1971, p. 189).

Existem inúmeras outras passagens no Emílio que podem nos servir de fonte interpretativa para uma teoria acerca da base estética, ou seja, sensível, dos nossos juízos ou pensamentos. E essa concepção, ao final das contas, se lhe dermos a devida atenção, não só nada deve à exposição criteriosa feita por Kant, como, na verdade, antecipa - sem a preocupação em explicitá-lo - até mesmo o sentido do que o filósofo alemão chamará, depois, de juízo de reflexão estético.

No Livro III do Emílio, ao esboçar a evolução intelectual de seu pupilo, Rousseau escreve: "No começo, nosso aluno só tinha sensações, e agora tem ideias; ele apenas sentia, agora julga" (ROUSSEAU, 1971, p. 144). A partir daí, Rousseau esforça-se para nos traçar a gênese das nossas ideias, e, tomando o cuidado estratégico de não antepor o juízo às sensações, começa por nos falar de como se originam as ideias simples, descrevendo-as, já então, como unidades de múltiplas sensações acumuladas, afinal, como ele mesmo nos diz, "as ideias simples são apenas sensações comparadas", ou seja, supõem reflexão. É o poder concebê-las - poder que decorre, evidentemente, da nossa necessidade de agrupar por semelhança nossas sensações para assim conseguir pensá-las - que explica, como foi dito faz pouco - a passagem da mera sensação, costumeiramente concebida como um estado em que o espírito é passivo, ao juízo, que exige uma faculdade ativa. Mas Rousseau, ao esmiuçar ainda mais a questão, embaralha-a, criando uma espécie de indistinção entre sentir e julgar, quando afirma: "Há juízos nas simples sensações, assim como nas sensações complexas, que chamo de ideias simples”. Embora sejamos induzidos pensar, nesse jogo entre sensações e ideias simples, na derivação das ideias de simples sensações, à moda de Hume, o caminho de Rousseau é, fundamentalmente, diferente. Isso porque, na verdade, é nas sensações simples, que jamais devemos confundir com as ideias simples, que vamos encontrar um elemento indispensável para a aqui suposta antecipação, em Rousseau, se não do conceito bem determinado, pelo menos do sentido para aquilo que Kant chama "juízo estético", pois as chamadas sensações simples são impressões de tal modo singulares, únicas, que ainda que possam ser representadas na forma de "ideias", nunca serão, mesmo sendo ideias, uma síntese - como o exige a correlação entre ideias simples e sensações complexas. Com isso, elas não têm, propriamente, a função de um conceito, sendo, por isso, tecnicamente falando, intuições, isto é, representações imediatas, diretas e concretas, ao invés de mediatas e abstratas.

Por isso, Rousseau afirma que na sensação simples, ou seja, singular, "o juízo é meramente passivo". Para quem está atento ao caráter espontaneamente ativo do juízo, ainda que se o tome como meramente associativo, o que é que isso pode significar, em termos de uma proposição lógica? Que nele, evidentemente, apesar da forma de um enunciado, não temos, no predicado, a afirmação ou a negação de uma propriedade objetiva do sujeito da proposição, que é sempre o objeto de que aí se fala. Aqui, por isso, o juízo é inteiramente subjetivo, pois, como explica Rousseau, na sensação simples o que torna o juízo passivo é o fato de que nele "se afirma que se sente o que se sente". Ou seja, não se diz o que se pensa sobre o que se sente. Nada se afirma, propriamente, do objeto que produz em nós a sensação, e o que se enuncia é uma impressão totalmente pessoal e, objetivamente falando, incomunicável. No fundo, como veremos, essa sensação é de um tipo especial, é um sentimento. Diferente do que ocorre com o juízo nas sensações simples, na ideia, justamente por esta implicar alguma espécie de síntese, a ação de julgar leva-nos a "aproximar, comparar, determinar relações que o sentido não determina", pelo menos não diretamente. Então, Rousseau completa: "Eis aí a única diferença, mas ela é grande". 


\title{
KANT, ROUSSEAU E AS BASES ESTÉTICAS | Pedro Paulo da Costa Corôa
}

Para ter-se uma ideia da pertinência, ou não, da relação entre essa análise das formas de juízo feita por Rousseau e o que foi fixado depois como juízo estético, basta lembrar o exemplo por ele dado:

\begin{abstract}
Vejo servirem a uma criança de oito anos um queijo gelado; ela leva a colher à boca sem saber do que se trata e, diante do frio, exclama: Ah, está me queimando! Experimenta uma sensação muito viva; não conhece nenhuma sensação mais viva que o calor do fogo, e acredita senti-la. Engana-se, no entanto; a impressão do frio a fere, mas não a queima, e as duas sensações não são semelhantes, pois quem experimentou uma e outra não as confunde. Portanto, não é a sensação que a engana, mas o juízo que faz sobre ela. (ROUSSEAU, 1971, p. 144-145).
\end{abstract}

Quer dizer, a criança toma como se fosse objetiva uma sensação totalmente subjetiva. Nesses casos, diz Rousseau,

se se contentar em dizer o que percebe, o que sente, sendo seu juízo meramente passivo, é impossível que se engane; mas quando julga a coisa pela aparência, é ativo, compara, estabelece por indução relações que não percebe; então, engana-se ou pode enganar-se. Para corrigir ou evitar o erro, precisa da experiência. (ROUSSEAU, 1971, p. 145).

Há outra passagem do Emílio, dessa feita no Livro IV, em que Rousseau demonstra uma perfeita compreensão das noções que entram no jogo de determinações de um juízo, de modo a caracterizá-lo em termos subjetivos ou objetivos, como juízo sensivelmente determinado ou como juízo lógico. Trata-se de uma nota em que Rousseau procura dar maior precisão a uma colocação por ele feita na obra. Após afirmar que "os atos da consciência não são juízos, mas sentimentos" e que "nossa sensibilidade é incontestavelmente anterior à nossa inteligência", afinal "tivemos sentimentos antes de ter ideias", Rousseau escreve, no rodapé:

Sob certos aspectos, as ideias são sentimentos e os sentimentos são ideias. Os dois nomes convêm a qualquer percepção que nos ocupe tanto com seu objeto quanto com nós mesmos que somos afetados por ele; apenas a ordem dessas afecções determina o nome que lhe convém. Quando ocupados principalmente com o objeto, só pensamos em nós por reflexão, trata-se de uma ideia; inversamente, quando a impressão recebida atrai a nossa primeira atenção e só pensamos por reflexão no objeto que a causa, trata-se de um sentimento. (ROUSSEAU, 1971, p. 201).

O que Rousseau nos diz nessa nota é a síntese impressionante da definição, elaborada por Kant, do juízo de gosto no $\S 1$ da Analítica do Belo. O texto, para efeito de comparação, diz o seguinte:

Para distinguir se algo é belo ou não, referimos a representação, não pelo entendimento ao objeto, para o conhecimento, mas pela imaginação [...] ao sujeito e ao seu sentimento de prazer ou desprazer. O juízo de gosto não é, pois, um juízo de conhecimento, portanto não é lógico, mas estético, pelo que se entende aquele cujo fundamento de determinação não pode ser outro do que subjetivo. (KANT, 2006: KU, AA 05: 203).

PPara concluir, gostaria de citar uma passagem de Júlia ou a nova Heloisa, Carta XII da primeira parte, que tem traços, diríamos, "schillerianos" pela função educativa que dá ao juízo de gosto e que, por isso mesmo, está diretamente associada ao vínculo aqui buscado entre Kant e Rousseau. Diz o trecho em questão: 
Sempre acreditei que o bom não era senão o belo posto em ação, que um estava intimamente ligado ao outro e que ambos tinham uma fonte comum na natureza bem ordenada. Resulta dessa ideia que o gosto se aperfeiçoa pelos mesmos meios que a sabedoria e que uma alma bem marcada pelos encantos da virtude deve proporcionalmente ser também sensível a todos os outros tipos de belezas. Podemos exercitar-nos para ver como para sentir, ou antes, uma vista refinada é apenas um sentimento delicado e fino. É assim que um pintor, diante do aspecto de uma bela paisagem ou diante de um belo quadro, extasia-se com coisas que nem são notadas por um expectador comum. Quantas coisas percebemos somente com o sentimento e de que é impossível explicar a razão? Quantos desses não sei quê que voltam tão frequentemente e de que só o gosto decide? O gosto é, de algum modo, o microscópio do julgamento, é ele que coloca os pequenos objetos ao seu alcance, e suas operações começam onde se detém as do último. Que é necessário então para cultivá-lo? exercitar-se para ver assim como para sentir e para julgar o belo por inspeção como o bom por sentimento. Não, afirmo que não depende nem mesmo de todos os corações o fato de se emocionar ao primeiro olhar de Júlia. (ROUSSEAU, 1964, p. 59). 
KANT, ROUSSEAU E AS BASES ESTÉTICAS | Pedro Paulo da Costa Corôa

\section{Referências}

ARISTÓTELES. De L'ame (Peri psyches). Paris: J. Vrin, 1995.

. Metafísica. São Paulo: Edições Loyola, 2002.

BAUDELAIRE, C. Oeuvres completes. Paris: Editions Robert Laffont, 1980.

CASSIRER, E. Kant und Rousseau. In: Rousseau, Kant, Goethe. Hamburg: Felix Meiner, $19 \overline{9} 1$.

. Rousseau, Kant, Goethe. Mexico: Fondo de Cultura Económica, 2007.

KANT, I. Schmitz, H.-C., Diel, M., Keul, G., Lenders, W. (Hgs). (2006). Die Akademie Ausgabe (AA) der Schriften Kants. Elektronische Kanttexte. IKP-Arbeitsbericht NF 18. Universität Bonn: Disponível em: <http:// www.ikp.uni-bonn.de/kant>. Acesso em: 05 jun. 2014.

Duas introduções à Crítica do Juízo. São

Paulo: Iluminuras, 1995.
PLATÃO. Protagoras. Paris: Les Belles Lettres, 1984. ROUSSEAU, J.-J. Oeuvres completes. Paris: Gallimard, 1964. Tome II. (Bibliothèque de la Pléiade).

Oeuvres completes. Paris: Aux Éditions Du Seuil. 1971. Tome III.

SCHILLER, F. Cultura estética e liberdade. São Paulo: Hedra, 2009. 